\title{
Comparative study on Toxoplasma infection between Malaysian and Myanmar pregnant women
}

Hemah Andiappan ${ }^{1}$, Veeranoot Nissapatorn ${ }^{1 *}$, Nongyao Sawangjaroen ${ }^{2}$, Myat Htut Nyunt ${ }^{3}$, Yee-Ling Lau ${ }^{1}$, Si Lay Khaing ${ }^{4}$, Khin Myo Aye ${ }^{3}$, Nan Cho Nwe Mon ${ }^{3}$, Tian-Chye Tan', Thulasi Kumar', Subashini Onichandran ${ }^{1}$ and Noor Azmi bin Mat Adenan ${ }^{4}$

\begin{abstract}
Background: Toxoplasma gondii, an obligate intracellular protozoan parasite, causes a disease called toxoplasmosis which can sometimes be acquired congenitally by a newborn from an infected mother. This study aimed to determine the seroprevalence of Toxoplasma infection and its associated risks among 219 and 215 pregnant women from Malaysia and Myanmar, respectively.

Methods: Anti-Toxoplasma lgG and IgM antibodies were screened by using standard commercial ELISA kits. The socio-demographic, obstetrics and risk factors associated with Toxoplasma infection data were compared between the two countries.

Results: The overall prevalence of Toxoplasma infection in Malaysian pregnant women (42.47\%; 95\% Cl=36.11-49.09) was significantly higher $(p<0.05)$ than Myanmar pregnant women $(30.70 \% ; 95 \% \mathrm{Cl}=27.92-37.16)$. By univariate analysis, this study identified that age group, education, parity, awareness on toxoplasmosis and consumption of undercooked meat were significantly associated $(p<0.05)$ with Toxoplasma seropositive Malaysian pregnant women but none of these factors associated with Toxoplasma seropositive Myanmar pregnant women. In comparison using univariate analysis between the two countries, it was found that Toxoplasma seropositive Malaysian pregnant women was associated with aged 30 years and above, secondary or lower-secondary level of education, the third trimester of pregnancy, having one child or more, lacking awareness of toxoplasmosis, absence of bad obstetrics history, having no history of close contact with cats or soil, living on a farm and also consumption of undercooked meat, unpasterized milk or untreated water. Avidity measurement was used to confirm the stages of Toxoplasma infection in pregnant women who were positive for both lgG and IgM antibodies and found all were infected in the past.

Conclusion: From our study, Toxoplasma screening and its risk measurement in pregnant women is firmly recommended for monitoring purposes and assisting proper management, including diagnosis and treatment during antenatal period. Also, it is necessary to initiate preventive measures for Toxoplasma infection among reproductive-age women in general and seronegative pregnant women in particular. Avidity measurement should be incorporated in Toxoplasma routine screening, especially with the availability of a single serum sample to assist in the diagnosis.
\end{abstract}

Keywords: Toxoplasma gondii, Seroprevalence, Risk factors, Avidity, Pregnant women, Malaysia, Myanmar

\footnotetext{
* Correspondence: nissapat@gmail.com

${ }^{1}$ Department of Parasitology, Faculty of Medicine, University of Malaya, 50603

Kuala Lumpur, Malaysia

Full list of author information is available at the end of the article
}

\section{Biomed Central}

(c) 2014 Andiappan et al.; licensee BioMed Central. This is an Open Access article distributed under the terms of the Creative Commons Attribution License (http://creativecommons.org/licenses/by/4.0), which permits unrestricted use, distribution, and reproduction in any medium, provided the original work is properly credited. The Creative Commons Public Domain Dedication waiver (http://creativecommons.org/publicdomain/zero/1.0/) applies to the data made available in this article, unless otherwise stated. 


\section{Background}

Toxoplasma gondii has a great impact on the human health generally, and more serious outcomes occur in immunocompromised and pregnant women specifically [1]. As reported in many previous studies, the infection sources are consumption of contaminated raw meat [2], water [3], fruits [4] and vegetables [5] or having close contacts with felines [6] and exposure to soil contaminated with cats' feces [7]. Infection during early pregnancy is more serious compared to infection in late gestation, but the likelihood of disease transmission increases during the progression of pregnancy [8]. Toxoplasma infection in the first trimester often causes abortion and late infection causes premature birth, or may lead to adverse complications in babies such as enlarged liver and spleen, eye damage from inflammation of the retina or other parts of the eye, jaundice, seizures, mental retardation and even death [9-11]. The detection of anti-Toxoplasma antibodies in pregnant women helps in disease management and the proper course of treatment. In recent years, the measurement of IgG avidity had been used to confirm the stages of Toxoplasma infection, either recent or past infection in pregnant women. Toxoplasma infection is prevalent in most countries and large populations in countries with tropical climates are affected. This study was conducted due to the fact that the seroprevalence of Toxoplasma infection in Malaysia pregnant women was recorded a decade ago [12] and no studies have been reported from Myanmar pregnant women [13]. Furthermore, Southeast Asia is a unique region where its local people share similar life styles, traditions and cultures, regardless of their socio-economic backgrounds. This study therefore aimed to demonstrate the current situation concerning the seroprevalence of Toxoplasma infection and to identify plausible risk factors among pregnant women from Malaysia and Myanmar. The information obtained could help in better understanding the epidemiological data on Toxoplasma infection between these two Southeast Asian nations. Also, it could further strengthen regional collaboration at a larger scale for initially eliminating the infection rate and later eradicating the disease burden of this enigmatic parasite from this region.

\section{Methods}

\section{Study site and population}

This is a prospective cross-sectional study. A total of 219 pregnant women visiting the antenatal clinic (ANC) in University Malaya Medical Centre (UMMC), Malaysia were recruited. UMMC is a government-funded medical institution located in Pantai Dalam, Kuala Lumpur, Malaysia. This hospital was founded in 1962 and has 866 beds. UMMC is a part of the University Malaya, a higher educational institution, and facilitates teaching, research and training for medical personnel. Meanwhile, a total of 215 pregnant women attending ANC at Yangon Central Women Hospital (YCWH), Myanmar were also recruited in this study (Figure 1). YCWH is a public hospital in Yangon, Myanmar, built for women's health care in the area. This hospital was founded in 1960 and has 750 beds. YCWH provides teaching facilities for the University of Medicine, Yangon, the Yangon Institute of Nursing and the University of Paramedical Science, Yangon. All eligible pregnant women at any gestational age gave informed consent before the commencement of this study.

All the participants' information related to sociodemographic such as their age, education level, occupation, gestation period, and parity and plausible risk-factors associated with toxoplasmosis (bad obstetrics history, presence of their own cats at home, presence of stray cats at home, consumption of undercooked meat, drinking unpasteurized milk, drinking untreated water, having contact with soil and living on a farm) were recorded in the formatted questionnaire forms. An operational definition was used for the risk factors. Bad obstetrics history was defined as a person having a history of miscarriage, still birth, premature labor, low birth weight, congenital anomalies or prenatal death in their previous pregnancy.

\section{Ethical consideration}

This study was conducted with the approval from the ethical review committee of the University of Malaya Medical Centre, Malaysia (EMC 901.1) and Ministry of Health, Department of Medical Research (Lower Myanmar), Myanmar (ERC Meeting 1/2011), in accordance with the Helsinky Declaration for the inclusion of human subjects in research.

\section{Serum sample collection}

Approximately $5 \mathrm{~mL}$ venous blood was drawn from the eligible pregnant women; sera were processed and were kept at $-20^{\circ} \mathrm{C}$ until testing.

\section{Detection of anti-Toxoplasma antibodies}

The serum was screened for anti-Toxoplasma IgG and IgM antibodies by using standard ELISA commercial kits (IgG-NovaLisa and IgM-NovaLisa, Dietzenbach, Germany) in accordance with the manufacturer's instruction. A positive sample for both anti-Toxoplasma IgG and anti-Toxoplasma IgM antibodies was also tested for its avidity using a standard ELISA commercial kit (IgG-NovaLisa Dietzenbach, Germany); high avidity indicates a past infection (of at least 4-5 months) and a low avidity indicates a recently acquired infection (within 4-5 months).

\section{Statistical analysis}

The data collected in the questionnaires and the serology results were analyzed by using statistical software SPSS version 17.0 (SPSS, Inc., Chicago, IL). The qualitative variables 


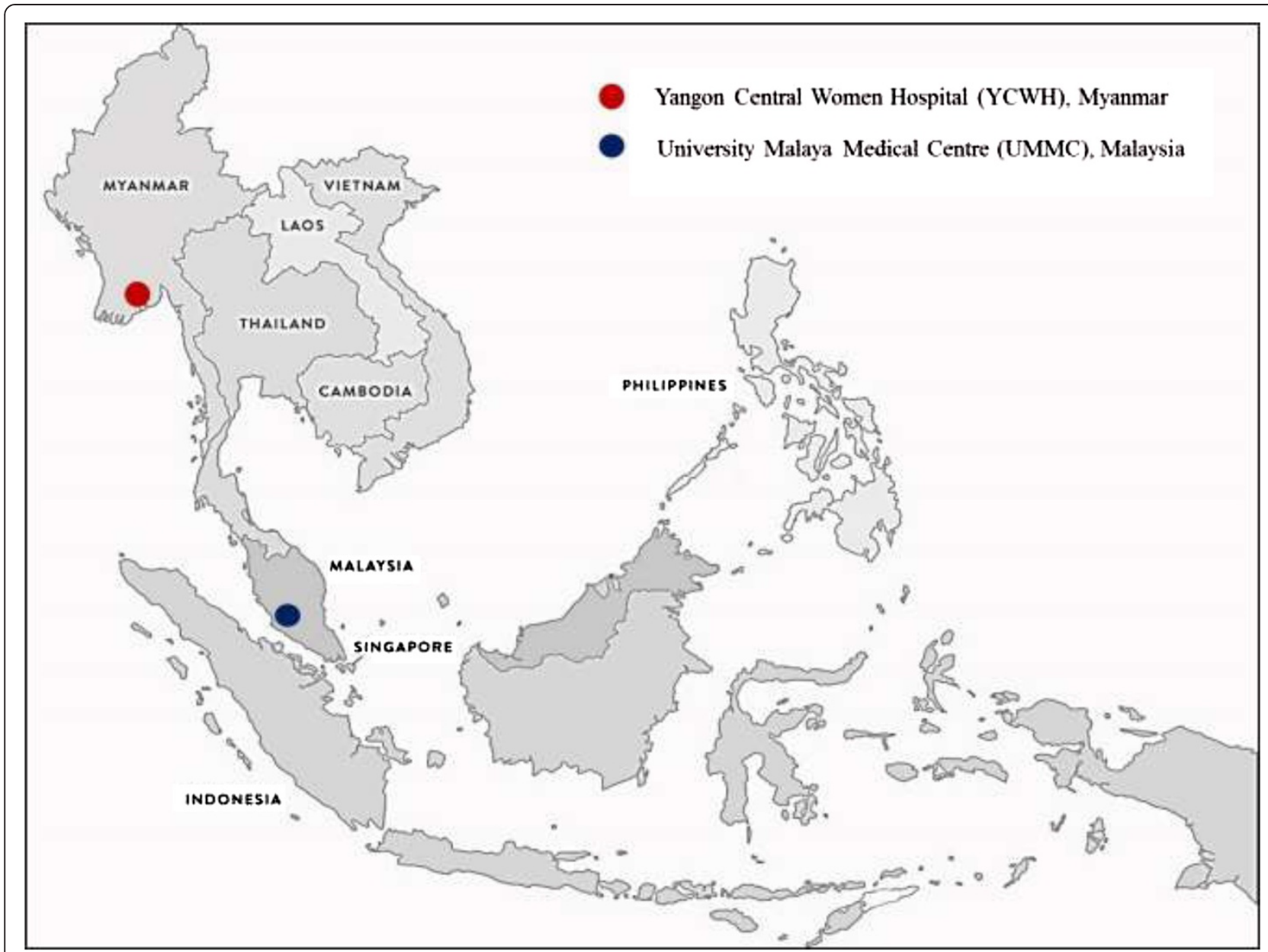

Figure 1 Study sites in Malaysia and Myanmar.

were estimated and presented as frequencies and percentages. Univariate analyses and the $x^{2}$ test were used to investigate the association between Toxoplasma seropositivity as a dependent variable and possible demographic and associated factors as independent variables. $p \leq 0.05$ was regarded as statistical significant.

\section{Results}

\section{Seroprevalence of Toxoplasma seropositivity and IgG} avidity measurement

The seroprevalence of Toxoplasma infection in Malaysian and Myanmar pregnant women is shown in Table 1. It was found that the seroprevalence of Toxoplasma infection in Malaysian pregnant women was significantly higher than in Myanmar pregnant women $(p<0.05)$. Furthermore, IgG avidity of 7 pregnant women (6 Malaysian and 1 Myanmar) who were positive for both the anti-Toxoplasma IgG and IgM antibodies indicated past Toxoplasma infection.

The associations between the demographic profiles and associated factors of Toxoplasma seropositivity in pregnant women from Malaysia and Myanmar

The age range of the pregnant women from Malaysia was 20 to 41 years with a mean of $30.07 \pm 4.43$ years while the pregnant women from Myanmar was 18 to 45 years with a mean of $29.46 \pm 5.50$ years. The majority of the pregnant women from Malaysia had higher education and were employed, but the majority of the pregnant women from

Table 1 Seroprevalence of Toxoplasma infection in pregnant women from Malaysia and Myanmar as assessed by ELISA

\begin{tabular}{llll}
\hline Anti-Toxoplasma antibodies & Malaysia $(\mathbf{N}=\mathbf{2 1 9})(\mathbf{n}, \%)$ & Myanmar $(\mathbf{N}=\mathbf{2 1 5})(\mathbf{n}, \%)$ & $65(30.23 \%)$ \\
\hline $\operatorname{lgG}^{+v e}$ & $87(39.73 \%)$ & $1(0.47 \%)$ & $\mathbf{p}$-value \\
$\operatorname{lgG}^{+v e}$ and $\operatorname{lgM}^{+v e}$ & $6(2.74 \%)$ & $66(30.70 \%)(95 \% \mathrm{Cl}=27.92-37.16)$ \\
Total & $93(42.47 \%)(95 \% \mathrm{Cl}=36.11-49.09)$ & 0.011 \\
\hline
\end{tabular}


Myanmar had only secondary or lower education and was unemployed. Most of the Malaysian pregnant women were in their third trimester and had one or more children but the Myanmar pregnant women were in their third trimester and expecting their first born. The association between Toxoplasma seropositive pregnant women and their demographic profiles and risk factors from each country were determined by univariate analysis. It was found that factors such as age group, level of education, parity, awareness on toxoplasmosis and consumption of undercooked meat shown significant associations $(p<0.05)$ with Malaysian pregnant women. Meanwhile, none of these variables played a significant role in Myanmar seropositive pregnant women (Table 2).

\section{Comparison of the association of demographic profiles and risk factors with Toxoplasma seropositive pregnant women between Malaysia and Myanmar}

The association between the seropositive pregnant women with their demographic profiles and risk exposures from Malaysia and Myanmar were compared by univariate analysis. Our findings showed that, Malaysian pregnant women were more prone to Toxoplasma seropositivity compared to Myanmar pregnant women, particularly pregnant women in the age group of 30 years and above, those who had secondary or lower level of education, were in their third trimester, had one or more than one child, lacked of awareness of toxoplasmosis, had no bad obstetrics history, did not own cats or have stray cats at home, did not consume undercooked meat, did not drink unpasteurized milk or untreated water and had no contact with soil or live on a farm (Table 3).

\section{Discussion}

Toxoplasma gondii causes severe impairment and even death to fetuses or to newborns through congenital infection. In this study, the seroprevalence of Toxoplasma infection among pregnant women was compared between two Southeast Asian countries, Malaysia and Myanmar. The statistic analysis indicated that pregnant women from Malaysia have significantly higher Toxoplasma seropositive rate when compared to pregnant women from Myanmar $(p<0.05)$. Toxoplasma seropositive in Malaysia pregnant women from this study $(42.49 \%)$ was similar to the previous study (49\%), conducted a decade ago [12]. Globally, reported prevalence of Toxoplasma infection varies, for example;, $48.6 \%$ in Albania [14], 68.6\% in Brazil [15], 10.6\% in China [16], 75\% in India [17], 10.3\% in Japan [18], $17.0 \%$ in Korea [19], 18.5\% in Netherlands [20], 40.8\% in Nigeria [21] and 38\% in Saudi Arabia [22]. Toxoplasma seropositivity in Malaysia were found to be higher than neighboring countries; being $28.3 \%$ in Thailand [23], 17.2\% in Singapore [24] and 7.7\% in Vietnam [25]. Meanwhile, data of Toxoplasma infection in
Myanmar is scanty as there was only one reported study of school children since 1977 [13] and no work has been published since. This is the first study conducted among pregnant women in Myanmar. The high Toxoplasma seropositive in both countries showed the need for routine screening for toxoplasmosis among women of childbearing age, and pregnant women in particular, for monitoring and preventive purposes.

Toxoplasma seropositivity in Malaysian pregnant women showed significant association with the demographic and potential risk exposure factors. The possibility of acquiring Toxoplasma infection was high in pregnant women in the age group of 30 years and above, with secondary or lower level of education and who had more than one child. A previous study also shown that prevalence of Toxoplasma infection increases by age [26], is associated with a low level of education [27] and having had more than one child [28]. Malaysian pregnant women with a lack of awareness on toxoplasmosis were more prone to acquire Toxoplasma infection. Knowledge and awareness about toxoplasmosis, as stated in many studies, may assist these pregnant women in protecting themselves from this parasitic infection [29-31]. As shown in many previous studies [32-34] consumption of undercooked meat (animal tissues may be contaminated by $T$. gondii cysts) is an important mode of disease transmission. Interestingly, our study showed that those who do not consume undercooked meat have higher Toxoplasma seropositivity. Based on this finding, it is suggested that further investigations are conducted before any conclusion could be made. Meanwhile, it is a different scenario with the Myanmar pregnant women. There was no statistically significant association found between the Myanmar seropositive pregnant women with the demographic profiles or risk exposures. Future studies with larger sample size and consideration of other confounding factors are needed to explain the acquisition of Toxoplasma infection in these Myanmar pregnant women.

The comparison between Malaysian and Myanmar seropositive pregnant women showed that Malaysian pregnant women were more prone to acquire Toxoplasma infection than Myanmar pregnant women. Besides the factors such as age group, level of education, parity and consumption of undercooked meat, the awareness on toxoplasmosis showed a significant association with Toxoplasma seropositivity in the comparison among the pregnant women between these two countries. Lack of awareness of toxoplasmosis might be due to lack of access to information related to Toxoplasma infection, especially amongst pregnant women. As T. gondii is a TORCH [acronym for a group of five infectious diseases namely; Toxoplasmosis, Others (Hepatitis B), Rubella (German measles), Cytomegalovirus (CMV), Herpes Simplex Virus (HSV)] infection, women in general, and pregnant women in 
Table 2 Univariate analysis on demographic profiles and associated factors of Toxoplasma seropositivity in Malaysian and Myanmar pregnant women

\begin{tabular}{|c|c|c|c|c|c|c|}
\hline \multirow[t]{2}{*}{ Variables } & \multicolumn{3}{|c|}{ Malaysia ( $N=219)$} & \multicolumn{3}{|c|}{ Myanmar (N = 215) } \\
\hline & Total (\%) & $\lg G^{+v e}(\%)$ & $p$-value & Total (\%) & $\operatorname{lgG}^{+v e}(\%)$ & $p$-value \\
\hline \multicolumn{3}{|l|}{ Age group } & 0.042 & & & 0.179 \\
\hline$<30$ & $107(48.9)$ & $38(35.5)$ & & $109(50.7)$ & $38(34.9)$ & \\
\hline$\geq 30$ & $112(51.1)$ & $55(49.1)$ & & $106(49.3)$ & $28(26.4)$ & \\
\hline \multicolumn{3}{|l|}{ Education } & 0.006 & & & 0.444 \\
\hline$\leq$ secondary & $74(33.8)$ & $41(55.4)$ & & $132(61.4)$ & $38(28.8)$ & \\
\hline$>$ secondary & $145(66.2)$ & $52(35.9)$ & & 83 (38.6) & $28(33.7)$ & \\
\hline \multicolumn{3}{|l|}{ Occupation } & 0.578 & & & 0.954 \\
\hline Employed & $178(81.3)$ & $74(41.6)$ & & $69(32.1)$ & $21(30.4)$ & \\
\hline Unemployed & $41(18.7)$ & $19(46.3)$ & & $146(67.9)$ & $45(30.8)$ & \\
\hline \multicolumn{3}{|l|}{ Gestation } & 0.684 & & & 0.144 \\
\hline $1^{\text {st }}$ trimester & $5(2.3)$ & $3(60.0)$ & & $6(2.8)$ & $4(66.7)$ & \\
\hline $2^{\text {nd }}$ trimester & $79(36.1)$ & $32(40.5)$ & & $95(44.2)$ & $27(28.4)$ & \\
\hline $3^{\text {rd }}$ trimester & $135(61.6)$ & $58(43.0)$ & & $114(53.0)$ & $35(30.7)$ & \\
\hline \multicolumn{3}{|l|}{ Parity } & 0.043 & & & 0.277 \\
\hline None & $42(19.2)$ & 12 (28.6) & & $125(58.1)$ & 42 (33.6) & \\
\hline$\geq 1$ & $177(80.8)$ & $81(45.8)$ & & $90(41.9)$ & $24(26.7)$ & \\
\hline \multicolumn{3}{|c|}{ Awareness on toxoplasmosis } & 0.005 & & & 0.179 \\
\hline Yes & $37(16.9)$ & $8(21.6)$ & & $4(1.9)$ & $0(0)$ & \\
\hline No & $182(83.1)$ & $85(46.7)$ & & $211(98.1)$ & $66(31.3)$ & \\
\hline \multicolumn{3}{|c|}{ Bad obstetrics history } & 0.907 & & & 0.217 \\
\hline Yes & $21(9.6)$ & $9(42.9)$ & & $13(6)$ & $2(15.4)$ & \\
\hline No & $198(90.4)$ & $84(42.4)$ & & $202(94)$ & $64(31.7)$ & \\
\hline \multicolumn{3}{|c|}{ Presence of own cats at home } & 0.489 & & & 0.387 \\
\hline Yes & $30(13.7)$ & $11(36.7)$ & & $40(18.6)$ & $10(25)$ & \\
\hline No & $189(86.3)$ & $82(43.4)$ & & $175(81.4)$ & $56(32)$ & \\
\hline \multicolumn{3}{|c|}{ Presence of stray cats at home } & 0.100 & & & 0.690 \\
\hline Yes & $17(7.8)$ & $4(23.5)$ & & $74(34.4)$ & $24(32.4)$ & \\
\hline No & $202(92.2)$ & $89(44.1)$ & & $141(65.6)$ & $42(29.8)$ & \\
\hline \multicolumn{3}{|c|}{ Consumption of undercooked meat } & 0.015 & & & 0.175 \\
\hline Yes & $22(10)$ & $4(18.2)$ & & $10(4.7)$ & $5(50)$ & \\
\hline No & $197(90)$ & $89(45.2)$ & & $205(95.3)$ & $61(29.8)$ & \\
\hline \multicolumn{3}{|c|}{ Drinking unpasteurized milk } & $*$ & & & 0.901 \\
\hline Yes & $0(0)$ & $0(0)$ & & $7(3.3)$ & $2(28.6)$ & \\
\hline No & $219(100)$ & $93(42.5)$ & & $208(96.8)$ & 64 (30.8) & \\
\hline \multicolumn{3}{|c|}{ Drinking untreated water } & * & & & 0.494 \\
\hline Yes & 0 & $0(0)$ & & $113(52.3)$ & 37 (32.7) & \\
\hline No & $219(100)$ & $93(42.5)$ & & $102(47.4)$ & 29 (28.4) & \\
\hline \multicolumn{3}{|l|}{ Contact with soil } & 0.351 & & & 0.366 \\
\hline Yes & 32 (14.6) & $16(50)$ & & $32(14.9)$ & $12(37.5)$ & \\
\hline No & $187(85.4)$ & $77(42.2)$ & & $183(85.1)$ & $54(29.5)$ & \\
\hline
\end{tabular}


Table 2 Univariate analysis on demographic profiles and associated factors of Toxoplasma seropositivity in Malaysian and Myanmar pregnant women (Continued)

\begin{tabular}{|c|c|c|c|c|c|c|}
\hline Living in the farm & & & 0.243 & & & 0.901 \\
\hline Yes & $1(0.46)$ & $1(100)$ & & $7(3.3)$ & $2(28.6)$ & \\
\hline No & $218(99.5)$ & $92(42.2)$ & & $208(96.7)$ & $64(30.8)$ & \\
\hline
\end{tabular}

*No variance of data.

particular, need to be educated about toxoplasmosis as prevention and control measures [29,35,36]. A total of approximately 1.2 million metric tons of cat feces were being deposited in the environment annually and the annual oocysts burden measured in a community survey was 3 to 434 oocysts per square foot, as reported in a study conducted in USA [37]. Exposure to the contaminated cat, its feces or contaminated soils may pose a risk to pregnant women. However, these Malaysian pregnant women had no contacts with cats (their own or stray cats), soils or did not lives on a farm. Meanwhile, many studies are being conducted on waterborne toxoplasmosis in recent years [38-41], highlighting the possibility of $T$. gondii transmission by the usage of oocysts contaminated water, especially for drinking purpose, but these reports contradict our finding on high Toxoplasma seropositivity in Malaysian pregnant women drinking treated water. There could be other confounding factors leading to the findings in this study and there is a need for further investigations. Meanwhile, these pregnant women should be educated [42] in order to prevent and control the acquisition of Toxoplasma infection by themselves and their fetus.

Table 3 Univariate analysis to compare the association between demographic profiles and risk factors with Toxoplasma seropositivity in Malaysian and Myanmar pregnant women

\begin{tabular}{ll}
\hline Variables (Malaysian) & Adjusted odd ratio (95\% Cl) \\
\hline Age $\geq 30$ years & $2.69(1.52-4.75)$ \\
Having $\leq$ secondary level of education & $3.07(1.70-5.56)$ \\
In $3^{\text {rd }}$ trimester & $1.70(1.01-2.87)$ \\
Having $\geq 1$ children & $2.32(1.33-4.03)$ \\
No awareness on toxoplasmosis & $1.93(1.28-2.91)$ \\
No bad obstetrics history & $1.59(1.06-2.40)$ \\
Absence of own cats at home & $1.63(1.06-2.50)$ \\
Absence of stray cats at home & $1.86(1.18-2.93)$ \\
No consumption of undercooked meat & $1.95(1.29-2.93)$ \\
No drinking unpasteurized milk & $1.66(1.12-2.47)$ \\
No drinking untreated water & $1.86(1.12-3.08)$ \\
No contact with soil & $1.67(1.09-2.57)$ \\
No living in Farm & $1.64(1.10-2.45)$ \\
\hline
\end{tabular}

All the Malaysian and Myanmar seropositive pregnant women acquired chronic Toxoplasma infection, supported by absence of clinical presentation in the fetus, false positive IgM results and confirmed by IgG avidity measurement. Avidity test proves to be a complementary tool in the diagnosis of toxoplasmosis among pregnant women. The persistence of IgM antibodies in the blood stream for many months up to a year, may lead to misdiagnosis of being primary acquired Toxoplasma infection, especially in the pregnant woman and her fetus [43]. Measurement of IgG avidity should be included in serological diagnosis, especially with a single serum sample of pregnant women for their first visit to the antenatal clinic to determine the staging of Toxoplasma infection consistent with clinical presentation.

\section{Conclusion}

The seroprevalence of Toxoplasma infection remains high in both Malaysia and Myanmar. The identified risks of exposure were found to be only associated with Toxoplasma seropositive pregnant women in Malaysia. Lack of awareness of toxoplasmosis was one of the factors contributing to high prevalence in these pregnant women from both countries. Hence, a routine screening for toxoplasmosis should be recommended for all women of reproductive age and pregnant women in early pregnancy for monitoring and preventive measures. Besides that, health education and related knowledge of risk exposure should be provided to the general population and pregnant women attending ante-natal clinics, in order to propagate awareness about Toxoplasma infection and to reduce the infection rate and its disease burden (multilingual brochures are attached as Additional file 1). Furthermore, IgG avidity measurement provides a useful tool for determining the staging of Toxoplasma infection and to assist in the course of treatment among pregnant women in general and in their early pregnancy in particular.

\section{Additional file}

Additional file 1: Health care education on toxoplasmosis in pregnant women.

Competing interests

The authors declare that they no competing interests. 


\section{Authors' contributions}

All authors were involved in the design of this study. VN and $\mathrm{MHN}$ were the principal investigators. VN, MHN, SLK, KMA, NCNM and NABMA drafted the protocol, consent forms and paper with input from the other authors. HA, SLK, KMA and NCNM were responsible for sample collection, serological analysis and data analysis. NS, TK and SO were responsible for statistical analysis and interpretation. LYL, NS, MHN, SLK, VN, TTC and NABMA were involved in data analysis, statistical analysis and interpretation and results discussion and inputs. All authors read and approved the final version of the manuscript.

\section{Acknowledgment}

We thank all the participating pregnant women for their informed consent, consistent support and cooperation throughout this study. We want to thank the doctors, nurses and staffs of the antenatal clinics at University Malaya Medical Centre, Malaysia and Yangon Central Women Hospital, Myanmar for their assistances and contribution in this study.

\section{Financial support}

This study was supported by University of Malaya High Impact Research Grant ((UM/MoHE High Impact Research; H-20001-00-E000061 and H-2000100-E000062) from the Ministry of Higher Education Malaysia, PV 049/2011B, PV 014/2012A and UMRG 544/14HTM.

\section{Disclosure}

This work was presented in the $8^{\text {th }}$ World Congress of the World Society for Pediatric Infectious Diseases-WSPID, Cape Town, South Africa. $18^{\text {th }}-22^{\text {nd }}$ November 2013

\section{Author details}

'Department of Parasitology, Faculty of Medicine, University of Malaya, 50603 Kuala Lumpur, Malaysia. ${ }^{2}$ Department of Microbiology, Faculty of Science, Prince of Songkla University, Hat Yai, Songkhla 90112, Thailand. ${ }^{3}$ Department of Medical Research (Lower Myanmar), Republic of the Union of Myanmar, Yangon, Myanmar. ${ }^{4}$ Department of Obstetrics and Gynecology, Faculty of Medicine, University of Malaya, 50603 Kuala Lumpur, Malaysia.

Received: 4 July 2014 Accepted: 24 November 2014

\section{Published online: 12 December 2014}

\section{References}

1. Halonen SK, Weiss LM: Toxoplasmosis. Handb Clin Neurol 2013, 114:125-145.

2. Boughattas S, Ayari K, Sa T, Aoun K, Bouratbine A: Survey of the parasite Toxoplasma gondii in human consumed ovine meat in Tunis city. PLOS One 2014, 9(1):e85044. doi: 10.1371/journal.pone.0085044. eCollection 2014.

3. Aramini JJ, Stephen C, Dubey JP, Engelstoft C, Schwantje H, Ribble CS: Potential contamination of drinking water with Toxoplasma gondii oocysts. Epidemiol Infect 1999, 122:305-315.

4. Alvarado-Esquirel C, Estrada-Martinez S, Liesenfeld O: Toxoplasma gondii infection in workers occupationally exposed to unwashed raw fruits and vegetables: a case control seroprevalence study. Parasit Vectors 2011, 4:235.

5. Yuksel P, Alpay N, Babur C, Bayar R, Saribas S, Karakose AR, Aksoy C, Aslan M, Mehmetali S, Kilic S, Balcioglu I, Hamanca O, Dirican A, Kucukbasmaci O, Oner A, Torun MM, Kocazeybek B: The role of latent toxoplasmosis in the aetiopathogenesis of schizophrenia-the risk factor or an indication of a contact with cat? Folia Parasitol (Praha) 2010, 57:121-128.

6. Du F, Zhang Q, Yu Q, Hu M, Zhou Y, Zhao J: Soil contamination of Toxoplasma gondii oocysts in pig farms in central China. Vet Parasitol 2012, 187:53-56.

7. Baquero-Artigao F, Del Castillo Martín F, Fuentes Corripio I, Goncé Mellgren A, Fortuny Guasch C, de la Calle Fernández-Miranda M, González-Tomé Ml, Couceiro Gianzo JA, Neth O, Ramos Amador JT: The Spanish society of pediatric infectious diseases guidelines for the diagnosis and treatment of congenital toxoplasmosis. An Pediatr (Barc) 2013, 79:116

8. Ben Abdallah R, Siala E, Bouafsoun A, Maatoug R, Souissi O, Aoun K, Bouratbine A: Toxoplasmosis mother-to-child screening: study of cases followed in the Pasteur Institute of Tunis (2007-2010). Bull Soc Pathol Exot 2013, 106:108-112.

9. Moncada PA, Montoya JG: Toxoplasmosis in the fetus and newborn: an update on prevalence, diagnosis and treatment. Expert Rev Anti Infect Ther 2012, 10:815-828.
10. Austeng ME, Eskild A, Jacobsen M, Jenum PA, Whitelaw A, Engdahl B: Maternal infection with Toxoplasma gondii in pregnancy and the risk of hearing loss in the offspring. Int J Audiol 2010, 49:65-68.

11. Sensini A: Toxoplasma gondii infection in pregnancy: opportunities and pitfalls of serological diagnosis. Clin Microbiol Infect Rev 2006, 12:504-512.

12. Nissapatorn $\mathrm{V}$, Noor Azmi MA, Cho SM, Fong MY, Init I, Rohela M, Khairul Anuar A, Quek KF, Latt HM: Toxoplasmosis: prevalence and risk factors. J Obstet Gynaecol 2003, 23:618-624.

13. Tin F: Serological responses to Plasmodium and Toxoplasma in school children from two areas in Burma. Southeast Asian J Trop Med Public Health 1977, 8:552-557.

14. Maggi Volpe A, Carito V, Schinaia N, Bino S, Basho M, Dentico P. Surveillance of toxoplasmosis in pregnant women in Albania. New Micobiol 2009, 32:89-92.

15. Sroka S, Bartelheimer N, Winter A, Heukelbach J, Ariza L, Ribeiro H, Oliveira FA, Queioz AJ, Alencar C Jr, Liesenfeld O: Prevalence and risk actor of toxoplasmosis among pregnant women in Fortaleza, northeastern Brazil. Am Trop Me Hyg 2010, 83:528-533

16. Liu Q, Wei F, Gao S, Jiang L, Lian H, Yuan B, Yuan Z, Xia Z, Liu B, Xu X, Zhu XQ: Toxoplasma gondii infection in pregnant women in China. Trans $R$ Soc Trop Med Hyg 2009, 103:162-166.

17. Chintapalli S, Padmaja IJ: Seroprevalence of toxoplasmosis in antenata women with bad obstetric history. Trop Parasitol 2013, 3:62-66.

18. Sakikawa M, Noda S, Hanaoka M, Nakayama H, Hojo S, Kakinoki S, Nakata M, Yasuda T, Ikenoue T, Kojima T: Anti-Toxoplasma antibody prevalence, primary infection rate, and risk factors in a study of toxoplasmosis in 4,466 pregnant women in Japan. Clin Vaccine Immunol 2012, 19:365-367.

19. Han K, Shin DW, Lee TY, Lee YH: Seroprevalence of Toxoplasma gondii infection and risk factors associated with seropositivity of pregnant women in Korea. J Parasitol 2008, 94:963-965.

20. Hofhuis A, van Pelt W, van Duynhoven YT, Nijhuis CD, Mollema L, van der Klis FR, Havelaar AH, Kortbeek LM: Decreased prevalence and age-specific risk factors for Toxoplasma gondii lgG antibodies in The Netherlands between 1995/1996 and 2006/2007. Epidemiol Infect 2011, 139:530-538.

21. Akinbami AA, Adewunmi AA, Rabiu KA, Wright KO, Dosunmu AO, Dada MO, Adeyemo TA: Seroprevalence of Toxoplasma gondii antibodies amongst pregnant women at the Lagos State University Teaching Hospital, Nigeria. Niger Postgrad Med J 2010, 17:164-167.

22. Almogren A: Antenatal screening for Toxoplasma gondii infection at a tertiary care hospital in Riyadh, Saudi Arabia. Ann Saudi Med 2011, 31:569-572

23. Nissapatorn V, Suwanrath C, Sawangjaroen N, Ling LY, Chandeying V: Toxoplasmosis-serological evidence and associated risk factors among pregnant women in southern Thailand. Am J Trop Med Hyg 2011, 85:243-247.

24. Wong A, Tan KH, Tee CS, Yeo GS: Seroprevalence of cytomegalovirus, toxoplasma and parvovirus in pregnancy. Singapore Med J 2000, 41:151-155.

25. Buchy P, Follézou JY, Lien TX, An TT, Tram LT, Tri DV, Cuong NM, Glaziou P, Chien BT: Serological study of toxoplasmosis in Vietnam in a population of drug users (Ho Chi Minh city) and pregnant women (Nha Trang). Bull Soc Pathol Exot 2003, 96:46-47.

26. Mwambe B, Mshana SE, Kidenya BR, Massinde AN, Mazigo HD, Majonge C, GroB U: Sero-prevalence and factors associated with Toxoplasma gondii infection among pregnant women attending antenatal care in Mwanza, Tanzania. Parasit Vectors 2013, 6:222.

27. Mostafavi SN, Ataei B, Nokhodian Z, Yaram M, Babak A: Seropeidemiology of Toxoplasma gondii in Isfahan province, central Iran: a population based study. J Res Med Sci 2011, 16:496-501.

28. Dattoli VC, Veiga RV, Cunha SS, Pontes-de-Carvalho L, Barreto ML, Alcantara-Neves NM: Oocyst ingestion as an important transmission route of Toxoplasma gondii in Brazilian urban children. J Parasitol 2011, 97:1080-1084

29. Amin TT, Ali MN, Alrashid AA, Al-Agnam AA, Al Sultan AA: Toxoplasmosis preventive behavior and related knowledge among Saudi pregnant women: an exploratory study. Glob J Health Sc 2013, 5:131-143.

30. Pereboom MT, Mannien J, Spelten ER, Schellevis FG, Hutton EK: Observational study to assess pregnant women's knowledge and behavior to prevent toxoplasmosis, listeriosis and cytomegalovirus. BMC Pregnancy Childbirth 2013, 13:98.

31. Alvarado-Esquivel C, Sifuentes-Alvarez A, Estrada-Martinez S, Rojas-Rivera A: Knowledge and practices on toxoplamosis in physicians attending pregnant women in Durango. Gac Med Mex 2011, 147:311-324. 
32. Lopes AP, Dubey JP, Neto F, Rodrigues A, Martins T, Rodrigues M, Cardoso L: Seroprevalence of Toxoplasma gondii infection in cattle, sheep, goats and pigs from the North of Portugal for human consumption. Vet Parasitol 2013, 193:266-269.

33. Hill DE, Dubey JP: Toxoplasma gondii prevalence in farm animals in the United States. Int J Parasitol 2013, 43:107-113.

34. Paştiu Al, Györke A, Blaga R, Mircean V, Rosenthal BM, Cozma V: In Romania, exposure to Toxoplasma gondii occurs twice as often in swine raised for familial consumption as in hunted wild boar, but occurs rarely, if ever, among fattening pigs raised in confinement. Parasitol Res 2013, 112:2403-2407.

35. Costa FF, Gondim AP, Lima MB, Braga JU, Vieira LJ, Araújo MA: Preventive behavior for toxoplasmosis in pregnant adolescents in the state of Ceara, Brazil. BMC Public Health 2012, 12:73.

36. Elsheikha HM: Congenital toxoplasmosis: priorities for further health promotion action. Public Health 2008, 122:335-353.

37. Torrey EF, Yolken RH: Toxoplasma oocysts as a public health problem. Trends Parasitol 2013, 29:380-384.

38. Verant ML, D'Ozouville N, Parker PG, Shapiro K, Vanwormer E, Deem SL: Attempted detection of Toxoplasma gondii oocysts in environmental waters using a simple approach to evaluate the potential for waterborne transmission in the Galápagos Islands, Ecuador. Ecohealth 2014, 11:207-214.

39. Gallas-Lindemann C, Sotiriadou I, Mahmoodi MR, Karanis P: Detection of Toxoplasma gondii oocysts in different water resources by Loop Mediated Isothermal Amplification (LAMP). Acta Trop 2013, 125:231-236.

40. Karanis P, Alderyarbi HM, Mirhashemi ME, Khalil KM: The impact of the waterborne transmission of Toxoplasma gondii and analysis efforts for water detection: an overview and update. Environ Sci Pollut Res Int 2013, 20:86-99.

41. Vaudaux JD, Muccioli C, James ER, Silveira C, Magargal SL, Jung C, Dubey JP, Jones JL, Doymaz MZ, Bruckner DA, Belfort R Jr, Holland GN, Grigg ME: Identification of an atypical strain of Toxoplasma gondii as the cause of a waterborne outbreak of toxoplasmosis in Santa Isabel do Ivai, Brazil. J Infect Dis 2010, 202:1226-1233.

42. Andiappan H, Nissapatorn V, Sawangjaroen N, Khaing SL, Salibay CC, Cheung MM, Dungca JZ, Chemoh W, Xiao Teng C, Lau YL, Mat Adenan NA: Knowledge and practice on Toxoplasma infection in pregnant women from Malaysia, Philippines and Thailand. Front Microbiol 2014, 5:291.

43. Oliver L, Montoya JG, Sandra K, Cynthia P, Remington JS: Effect of testing for lgG avidity in the diagnosis of Toxoplasma gondii infection in pregnant women: experience in a US reference laboratory. $J$ Infect Dis 2001, 183:1248-1253.

\section{Submit your next manuscript to BioMed Central and take full advantage of:}

- Convenient online submission

- Thorough peer review

- No space constraints or color figure charges

- Immediate publication on acceptance

- Inclusion in PubMed, CAS, Scopus and Google Scholar

- Research which is freely available for redistribution 